\title{
Assessment of sustainability indicators for urban water infrastructure in a developing country
}

\begin{abstract}
Purpose: This research aims to study a broad range of sustainability aspects and develop a set of indicators with their subjective relevance to each of the sustainability dimensions that will help to improve the sustainability level of the water system of Nur-Sultan (Kazakhstan).
\end{abstract}

Design/Methodology/Approach: The broader list of indicators (which were identified through a thorough review of the literature) was assessed by water-related industry professionals and experts who were asked to assess the compliance of suggested indicators to five criteria of sustainability using a Likert scale.

Findings: It was found that the highest-ranked indicators across all five categories were mainly related to the chemical and physical quality of water, followed by availability of individual water meters as well as water supply tariffs' adjustment to users' income, and issues of ageing infrastructure. The lowest-ranked indicators among all categories were mainly related to investments into research and development, water management and awareness, feedback systems and flexibility. The least ranked indicators are seen to be more related to the scenarios when basic needs are covered and the stakeholders have extra time and resources for advancing the levels of water infrastructure sustainability.

Implications: The ranked and categorized indicators can be used as a powerful decision-making tool to improve the sustainability of the water system of Nur-Sultan or any other city in a developing country

Originality: By conducting this study, it was aimed to address the aforementioned gap in the field in terms of running a wider scope assessment of indicators rather than looking at conventional environmental and socio-economic aspects. This provides novelty to the study, especially in the context of developing countries that need more guidance in terms of sustainable development of the water-related infrastructure.

Keywords: water use; sustainability indicators; sustainability dimensions; urban water infrastructure.

\section{Introduction}

In recent years, in line with global trends, Kazakhstan has faced continuous population growth, urbanization, and rapid consumption of natural resources (Tokbolat, Karaca, Durdyev, \& 
Calay, 2019). A particular pressure on resources such as energy, water, and materials can be observed in the fast-growing capital of Kazakhstan, Nur-Sultan. With the predicted two-fold increase of the city's population by 2050 and various consequences of climate change evident from the recent years, it is foreseen that Nur-Sultan city will face significant pressure on its resources, specifically, on the water system (Asian Development Bank, 2018). Various measures have been implemented not only to provide a sufficient amount of potable and non-potable water but also to enhance the sustainability level of the overall water system (Asian Development Bank, 2018). Despite such measures, there is still an array of issues ranging from unsustainable treatment and distribution of water to poor water management.

Nur-Sultan city, the capital of Kazakhstan, with its rapidly growing population, is facing significant pressure in terms of water demand. With the anticipated two-fold population increase by 2050 to reach 2 million inhabitants, the city's demand for adequate water supply as well as well-functioning sanitation systems is expected to grow, respectively. The city has an ageing infrastructure and inadequate water management systems, and it suffers approximately $20 \%$ of water loss (Asian Development Bank, 2018). Decent and well-functioning infrastructure for the provision of potable and non-potable water, as well as water treatment, is crucial for the sustainable development of any urban settlement.

Sustainable development requires consideration of an array of aspects ranging from social, economic, environmental, health, technological to cultural (Durdyev \& Tokbolat, 2021; Lundin, 2003). Among others, sustainability requires ensuring that every individual has access to clean water and an acceptable quality of sanitation if the society wants to achieve healthy development (García-Cáceres, Castañeda-Galvis, \& Suárez-Fajardo, 2019).

It was observed that there is a lack of literature regarding the sustainability assessment of urban water systems. While most of the considered studies based their sustainability assessment on the environmental or economic dimensions, only a very few of them took into account all the sustainability dimensions, including socio-economic, environmental, technological, and institutional aspects (Durdyev, Zavadskas, Thurnell, Banaitis, \& Ihtiyar, 2018; Lundin, 2003). Also, a considerable share of the studies look at identifying sustainability indicators for water management, but very few focused on urban water infrastructure specifically (Spiller (2016). The study aims to create a comprehensive list of ranked water infrastructure-related sustainability indicators that could be used by relevant stakeholders in Nur-Sultan city for ensuring sustainable 
development in the field. By conducting this study, it was aimed to address the aforementioned gap in the field in terms of running a wider scope assessment of indicators rather than looking at conventional environmental and socio-economic aspects. This provides novelty to the study, especially in the context of developing countries that need more guidance in terms of sustainable development of the water-related infrastructure.

At the same it is envisaged that the output of the study will provide a ranked set of sustainability indicators specifically concerned about water infrastructure rather than mere water management, thus, addressing another gap in the field mentioned before. Finally, it should be borne in mind that this study is very novel for Kazakhstan's water infrastructure-related field as most of the standards, norms and technologies are quite outdated and based on Soviet times' regulations and solutions from 30-40 years ago.

Therefore, the main objective of this study is to develop a comprehensive list of ranked and prioritized indicators that cover essential aspects of sustainability for urban water systems in Nur-Sultan. This is achieved by identifying and evaluating a set of sustainability indicators' conformity to 5 sustainability criteria and prioritizing them by giving weight based on survey results conducted among experts and professionals in the field. It should be noted that the study will have a limitation in terms of the selection of water infrastructure-related experts. Most of them were from Kazakhstan and adding international experts would have provided a wider range of knowledge and expertise. Nevertheless, the actual selection of experts was balanced and wellthought in terms of their professional focus areas and backgrounds as well as knowledge and experience, thus, providing informed and unbiased opinions.Methodology Sustainability indicators (SIs) are considered assessment tools that measure a system's progress towards sustainability (Lundin, 2003). The principal objective of SIs is to help policy and decision-makers in contributing to the development of society sustainably according to the United Nation's Sustainable Development Goals (Waas et al., 2014). In this study, a set of indicators was established based on a literature review, followed by the subdivision of the set of indicators into sustainability categories (dimensions). Finally, the list of identified indicators was assessed by a panel of experts using a questionnaire-based survey. The survey results were used to analyze the data and categorize the SIs in accordance with their importance. 


\section{The initial selection of indicators through a literature review}

To identify the preliminary set of indicators, this research performed an extensive literature review of scientific publications, databases, and websites of relevant organizations. As a result, an extensive list of possible indicators was found and examined in detail and after a preliminary assessment of their relevance to sustainability principles, and only 28 of them were selected for further analysis (Table 1). Such a pre-selection was necessary since water-related indicators can be used for different purposes. For example, the study by Jensen and Wu (2018) aimed at developing a set of indicators for urban water security. Another study by Spiller (2016) aimed at identifying adaptive capacity indicators for the assessment of urban water systems' sustainability. Several indicators were repeatedly encountered across studies, and therefore, were noted. The challenge of this study was related to the selection of an optimal number of indicators for further analysis. Having too many or too small numbers would negatively affect the manageability and clarity of the results. As stated in several studies by Gilbert (1996), Harger and Meyer (1996), Smith and Zhang (2004), Lundin (2003), Lehtonen (2012), Seaford (2013), a final selection of sustainability indicators requires ensuring that they conform to specific characteristics. Based on the literature mentioned above, this study took into account a number of characteristicswhile choosing indicators for further analysis. The shortlisting process was carried out manually by the authors following the characteristics indicated in Figure 1.

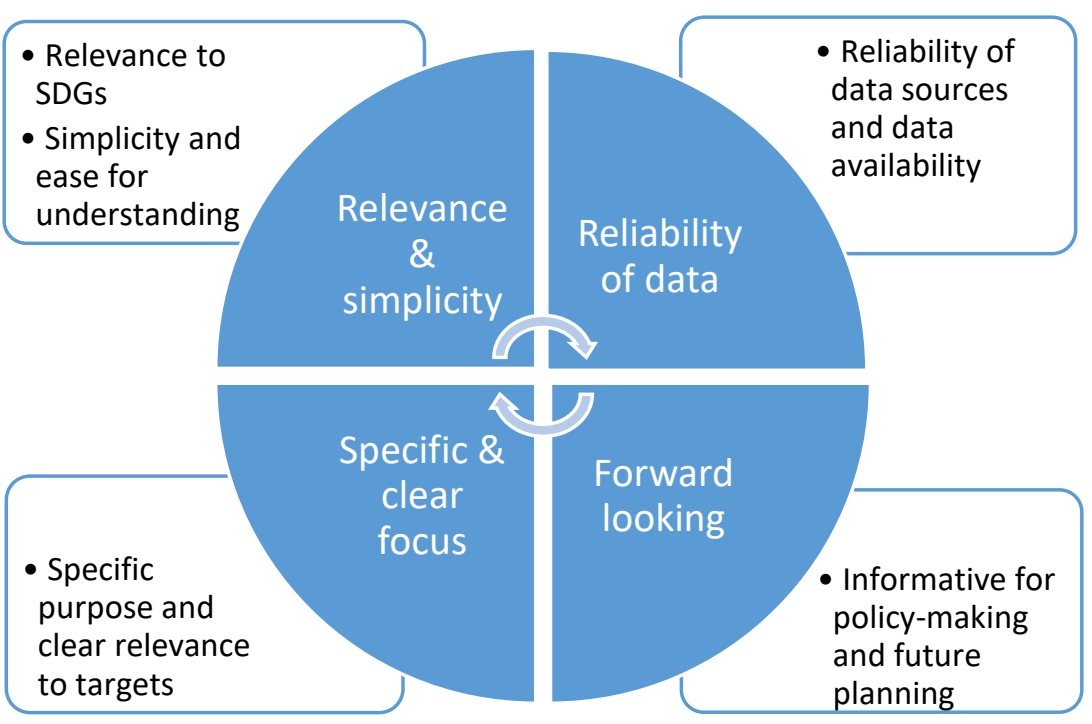

Figure 1. Characteristics used for the development of the preliminary set of indicators. 
Table 1. The list of the identified indicators from the literature

\begin{tabular}{|c|c|c|}
\hline IND & Sustainability Indicators & References \\
\hline IND1 & Investment in treatment and water management & $\begin{array}{l}\text { Brelih, Rajkovič, Ružič, Rodič, } \\
\text { and Kozelj (2019) }\end{array}$ \\
\hline IND2 & Investment in the construction of new water & Brelih et al. (2019) \\
\hline IND3 & $\begin{array}{l}\text { Operation and maintenance cost of existing water } \\
\text { infrastructure }\end{array}$ & Milman and Short (2008) \\
\hline IND4 & Investment to research and development & Spangenberg (2008) \\
\hline IND5 & Water supply tariff related to users' income & Leflaive and Hjort (2020) \\
\hline IND6 & Coverage with an individual water meter & Leflaive and Hjort (2020) \\
\hline IND7 & Access to water supply & Harger and Meyer (1996) \\
\hline IND8 & Access to improved sanitation & $\begin{array}{l}\text { Harger and Meyer (1996); Pires } \\
\text { et al. (2017) }\end{array}$ \\
\hline IND9 & Water availability per capita per day & Venkatesh and Brattebø (2013) \\
\hline IND10 & $\begin{array}{l}\text { Availability of efficient services for user } \\
\text { complaints and requirements }\end{array}$ & $\begin{array}{l}\text { Marques, da Cruz, and Pires } \\
(2015)\end{array}$ \\
\hline IND11 & Public education and awareness & Harger and Meyer (1996) \\
\hline IND12 & Incidence of water-related diseases & $\begin{array}{l}\text { Asian Development Bank } \\
(2018)\end{array}$ \\
\hline IND13 & Existence of water-related policies & Lehtonen (2012) \\
\hline IND14 & $\begin{array}{l}\text { Compliance with the international water quantity } \\
\text { and quality standards }\end{array}$ & Spiller (2016) \\
\hline IND15 & $\begin{array}{l}\text { Compliance of water supply systems with sanitary } \\
\text { regulations }\end{array}$ & Lehtonen (2012) \\
\hline IND16 & Separate storm-water systems & Milman and Short (2008) \\
\hline IND17 & Aging of infrastructure assets & Pires et al. (2017) \\
\hline IND18 & $\begin{array}{l}\text { Efficient operation and maintenance of water } \\
\text { infrastructure systems }\end{array}$ & Bagheri and Hjorth (2007) \\
\hline IND19 & Capacity of drinking water reserves & $\begin{array}{l}\text { Balkema, Preisig, Otterpohl, } \\
\text { and Lambert (2002) }\end{array}$ \\
\hline IND20 & Flexibility/adaptability of water systems & Balkema et al. (2002) \\
\hline IND21 & Land/space requirement & $\begin{array}{l}\text { Balkema, Preisig, Otterpohl, } \\
\text { and Lambert (2002) }\end{array}$ \\
\hline IND22 & Reliability/continuity of water supply & Spiller (2016) \\
\hline IND23 & $\begin{array}{l}\text { Monitoring leakages and water loss from the water } \\
\text { supply system }\end{array}$ & Spiller (2016) \\
\hline
\end{tabular}




\begin{tabular}{|l|l|l|} 
IND24 & Chemical quality of drinking water & $\begin{array}{l}\text { Danilenko, Van den Berg, } \\
\text { Macheve, and Moffitt (2014) }\end{array}$ \\
\hline IND25 & Physical quality of drinking water & Danilenko et al. (2014) \\
\hline IND26 & Water reclamation and reuse & Spiller (2016) \\
\hline IND27 & Local rainwater harvesting & Spiller (2016) \\
\hline IND28 & Frequency of natural disasters & Jensen and Wu (2018) \\
\hline
\end{tabular}

\section{Categorization of indicators according to sustainability categories (dimensions)}

Once the initial list of 28 indicators was compiled (Table 1), the next step was to subdivide them according to sustainability categories (dimensions) in order to perform further assessments. The developed structure where sustainability indicators were sub-divided under categories (dimensions) is referred to as a framework. A framework in this context is defined as a structure used for integrating the information necessary for the stated purpose, which helps to choose relevant indicators (Jensen \& Wu, 2018). Sustainable development usually embraces three main dimensions, namely, Environmental, Economic, and Social. However, sometimes it can comprise additional dimensions, including institutional or technical aspects (Lundin, 2003). Most of the studies mainly focus on the environmental dimension only without taking into consideration other vital components of sustainable development and how they are related to any selected indicator (Jensen \& Wu, 2018) Lundin, 2003) . For this reason, this study attempted to suggest a new, more comprehensive framework, which includes various dimensions of sustainable development, namely environmental, social, economic, technological, and institutional. According to Juwana, Muttil, and Perera (2012), Pires et al. (2017), Spangenberg (2008), these sustainability dimensions are defined below. Identified indicators were categorized under each of the sustainability dimensions and presented in Figure 2. 


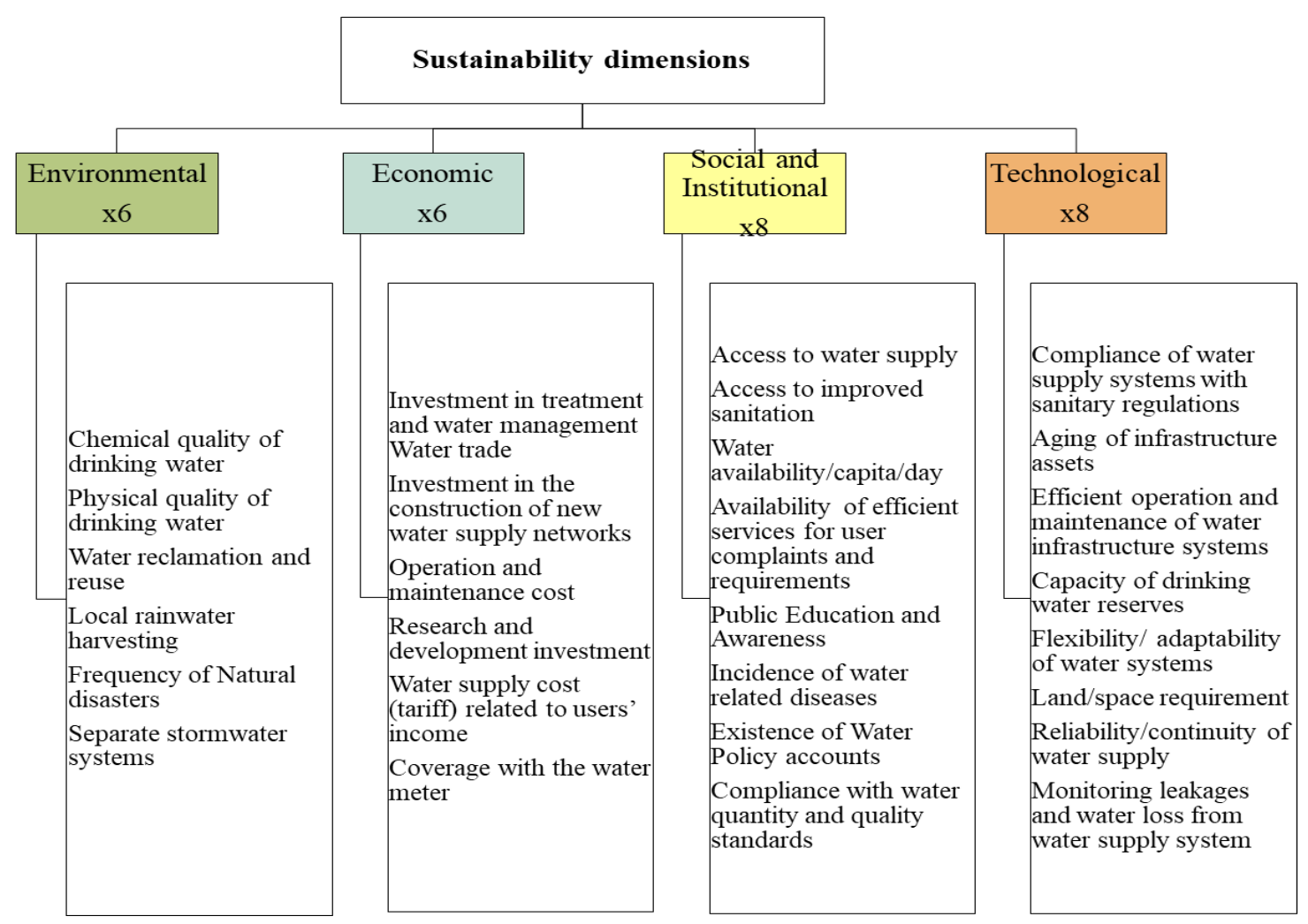

Figure 2. Categorization of the sustainability indicators

According to Juwana et al. (2012), Pires et al. (2017), Spangenberg (2008), Lundin (2003), the Environmental Sustainability concept refers to aspects that contribute to environmental protection and efficient use of resources such as water, soil, and air (Durdyev, Zavadskas, et al., 2018). The main idea of environmental sustainability is to sustain the long-term development of the environment by preventing the excessive extraction of natural resources and decreasing the emissions into the atmosphere. Economic Sustainability refers to principles and actions which deliver economic progress by an efficient allocation of resources to meet societal needs; economic sustainability ensures efficient utilization of water for urban development. Social Sustainability aims to provide society's socio-cultural development. It secures equal access to safely managed water supplies of reasonable quality and amount, which is sufficient to cover basic human needs. Institutional sustainability is associated with administrative and social procedures, legal norms, political decision-making, and implementation within a country, including the water management system. The technological Sustainability dimension is used to ensure an adequate technological framework necessary for the development and maintenance of urban water infrastructure.

\section{Research Method}


The study adopts a mixed-method, which comprises qualitative and quantitative approaches to achieve its aim (Durdyev, Ismail, \& Kandymov, 2018). As the first objective of the study, the literature in the field was comprehensively reviewed to recognize the indicators, which were then used to design the questionnaire survey. The questionnaire contains three sections, while a number of open and closed-ended questions are included to provide the target population to express their opinions. The first section aimed to obtain general information on the background of respondents on aspects such as the length of their experience in the field, the type of industry, organization, and the focus area of their work. In the second section, the questionnaire included 28 questions, each asking to score the importance of each indicator to see its contribution to sustainability assessment of water infrastructure. The evaluation process was based on a 5-point Likert scale (1- not significant, 5- highly significant) in which the experts were able to give weights to the indicators based on their level of conformity to the environmental, economic, social, institutional, and technological dimensions.

According to Sullivan and Artino Jr (2013), this type of question helps to see how far the participants agree or disagree with a specific statement; in this case, their opinion would show how important is each indicator in terms of the five categories. In the third section, the participants were asked to comment on the application of these indicators in water-related projects in NurSultan and to suggest indicators that they would include in the future. The indicators were located in the questionnaire in a random order to avoid the impression that they were preliminarily ranked. The survey was intended to be simple and easy to understand. To ensure that, a pilot test is conducted to test and amend any limitations in the design of the questionnaire before its administration, as suggested by Pires et al. (2017). Five experts from the academic sector, including professors and graduate students with an engineering background, expressed their willingness to participate in the pilot test. The test aimed to check the clarity of the questions and terminology used as well as estimate the time needed to complete the survey. As a result of the pilot study, several suggestions and comments were taken into consideration, and the pilot study validated the feasibility of the questionnaire in this study.

To ensure that selected indicators satisfy the principles of sustainability, it was necessary to run a survey among local water industry-related professionals and experts in Nur-Sultan. As this study includes subjective opinion-based judgments, the choice of the survey respondents is a critical issue that requires the justifications of selecting them. Therefore, specific criteria 
regarding respondents, as mentioned in the study of Cloquell-Ballester, Cloquell-Ballester, Monterde-Diaz, and Santamarina-Siurana (2006) were taken into account: i) the level of expertise and relevant knowledge of the subject area; ii) interest and ability to participate in the survey, and iii) the capability to perform the task. It is assumed that the main factors affecting the ranking of the indicators were dictated by their background knowledge and experience. Nearly 100 experts were identified from different categories based on a preliminary desktop-based research activity by considering various water sector-related professionals. Internet profiles as well as referrals and comparing with the aforementioned three selection criteria. As a result, professors with an environmental engineering background, government officials and professionals, community representatives, and other stakeholders from the water infrastructure sector, were identified and contacted for administering the survey (Pires et al., 2017; Singh, Murty, Gupta, \& Dikshit, 2009). The experts were contacted either by email, phone calls, or in person. The questionnaire was supported by background information on research content and its objectives for the ease of understanding by respondents. Out of 100 experts that were approached only 22 agreed and participated in the survey, which gives a $22 \%$ response rate. Although the number of respondents is low, the experts had sufficient knowledge of urban water system issues and extensive experience in water-related projects in both local and international contexts. Thus, this helped to avoid any superficial responses and mitigate the potential issue of bias in the results.

\section{Results and analysisDemographic background}

The results of the first section of the questionnaire provide general information on the background and expertise of the survey respondents. As illustrated in Figure 3, the majority of the experts are well-experienced with 15 or more years (27\%), 7-10 years (27\%), 5-6 years (23\%), 25 years (14\%), 1-2 years $(9 \%)$ respectively. The majority of the respondents indicated that they work for non-governmental organizations $(46 \%)$, whereas the rest is representing governmental (27\%) and commercial (27\%) organizations, respectively. The further breakdown of the respondents' pool according to industry affiliation, the majority of respondents indicated to work in hydrology sector (41\%), ecology (32\%), education (9\%), economy (9\%), construction (5\%) and energy $(5 \%)$ as shown in Figure 3. 


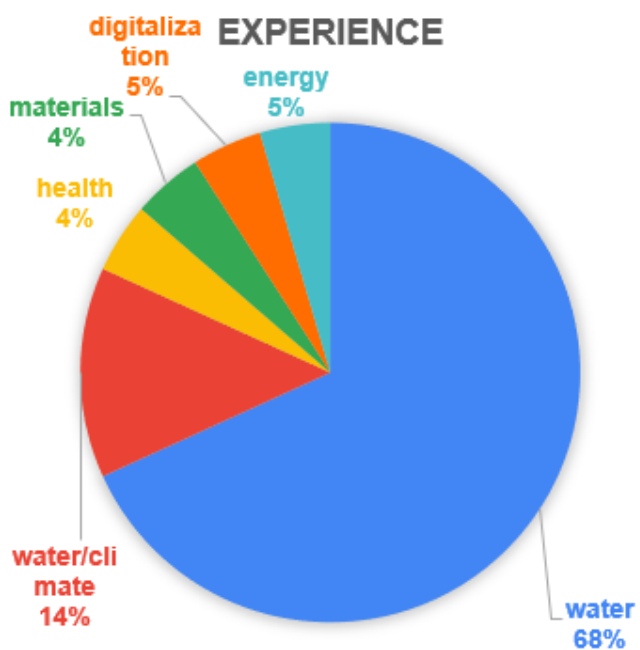

FOCUS AREA OF WORK

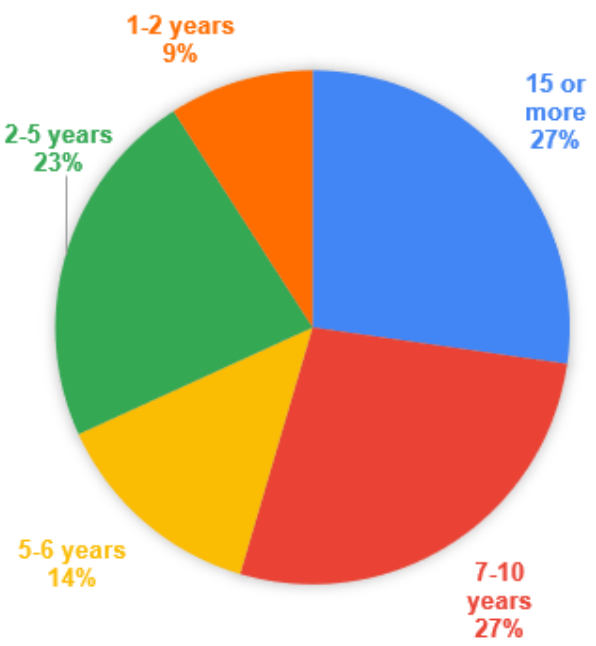

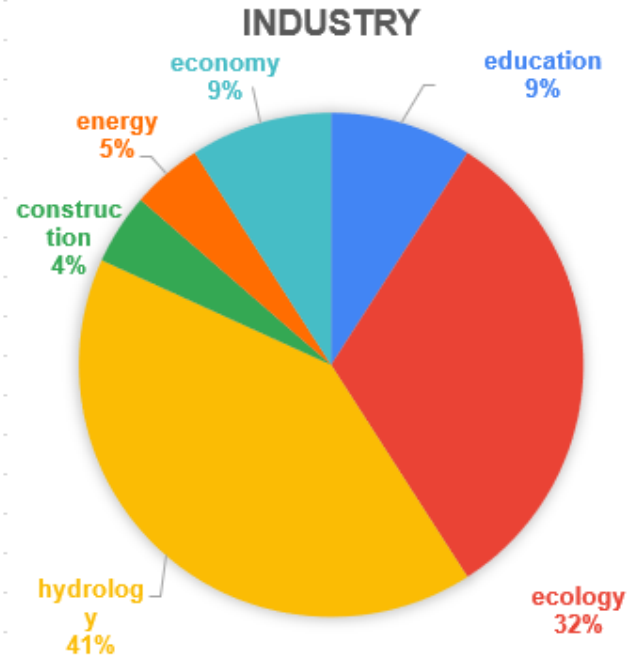

AFFILIATION

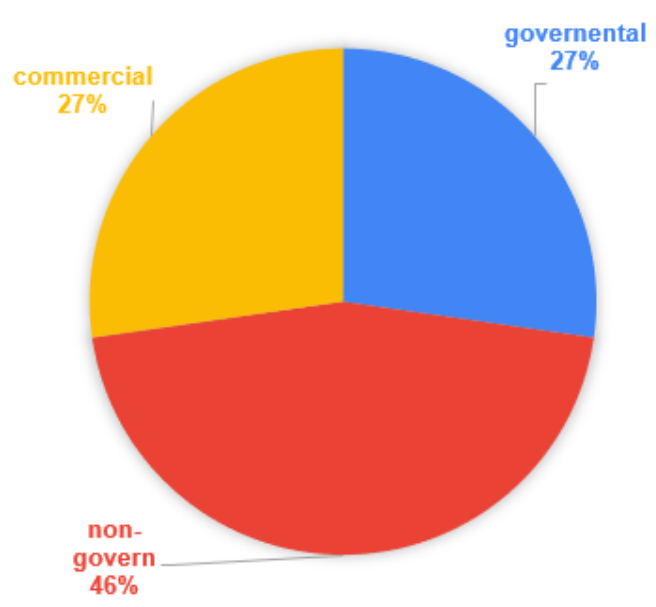

Figure 3. Respondents' experience, industry, affiliation and focus area of work

\section{Data analysis}

The data collected from the survey was further analyzed based on statistical analysis, and the results were processed according to the method described in the study of Pires et al. (2017). This approach allows estimating the point averages given by each expert to indicators, and specifically, to each out of five sustainability criteria. The multi-attribute method (as a widely used approach) aligns with the aim of the present research, which is used to evaluate and rank the identified indicators, as recommended by many researchers (Durdyev \& Ismail, 2019; Durdyev \& Mbachu, 2011). 


$$
M R_{j}=\sum_{1}^{5}\left(R_{p_{j n i}} \times \% R_{j n}\right) \quad(E q .1)
$$

The most important indicator represents the highest MR (mean rating) value, which is computed using Eq. 1. As recommended by Fellows and Liu (2015), for the indicators used to form a scale in correlation "with one another, the indicators should measure the same element". If an indicator scored 3-5 for any of the sustainability dimensions, it would illustrate that this indicator belongs to that specific sustainability dimension (environmental, economic, social, institutional or technological) and can be considered as significant (Pires et al., 2017). Chronbach's alpha ( $\alpha$ ) (a measure of scale reliability (Tavakol \& Dennick, 2011)) was also computed to test the data reliability. The $\alpha$ that is calculated for each dimension is higher than 0.9, which indicates high data reliability. Figures 4-8 illustrate the respective ranking of sustainability indicators (SI) using the Likert scale (from 1 being "Not significant" to 5 being "Very significant") in terms of each sustainability criteria (environmental, economic, social, technological, institutional).

The indicator rating scores ranged from a minimum of 2.27 to a maximum of 5 . It is essential to note that there was no indicator, which scored less than 2.0 and was evaluated as "Not significant," and it indicates that most of the indicators were rated as important and can be further used for the urban infrastructure projects in Nur-Sultan. However, since the study aimed to categorize the indicators according to their importance, it was decided to rank them based on the highest score in terms of each sustainability criteria.

In terms of the ranking of environmental indicators, it can be seen from Figure 4 IND24 “Chemical quality of drinking water" (4.0), IND25 "Physical quality of drinking water" (3.86), IND28 "Frequency of natural disasters" (3.73), IND15 "Compliance of water supply systems with sanitary regulations" (3.68) and IND8 "Access to improved sanitation" (3.59) were ranked as the highest among all 28 indicators. From the ranking results, it can be observed that the two highestranked indicators in this dimension were related to the quality of drinking water which was expected due to the commonality of quality-related issues in Nur-Sultan city. These were followed by the issues related to natural disasters and sanitation both of which tend to be a concerning issue for the city residents. The lowest-ranked indicators in this category are IND4 "Investment to research and development" (2.27), IND3 “Operation and maintenance cost of existing water infrastructure" (2.50), IND10 "Availability of efficient services for user complaints and requirements" (2.55), IND11 "Public education and awareness" (2.59), IND1 "Investment in 
treatment and water management" (2.64). The least important indicators, in the experts' opinions, are related to investments into $R \& D$ or general investments, maintenance costs, systems allowing customers to report their issues and awareness related aspects. If the R\&D, complaints and awareness issues are clear demands of the higher level, it is not clear why the maintenance costs were ranked low. In fact, maintenance costs of water infrastructure could be directly affecting the quality of water which was a big concern for the respondents.

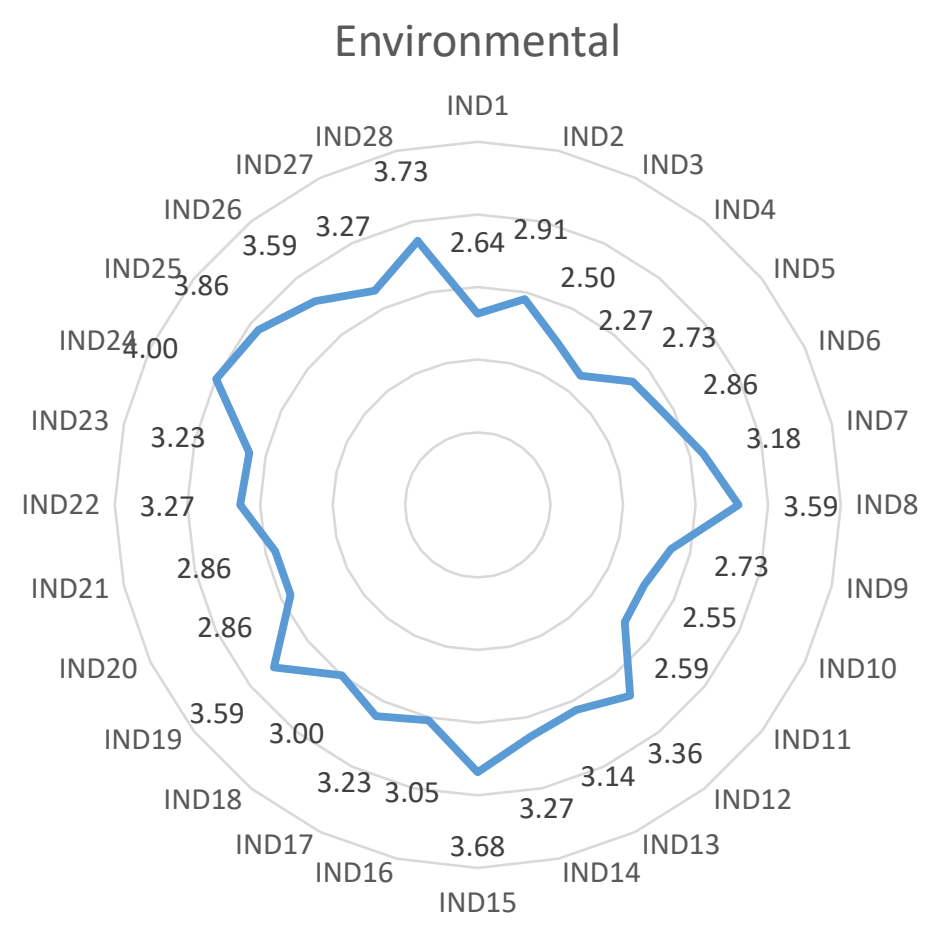

Figure 4. Ranking of environmental indicators

In terms of the ranking of economic indicators, Figure 5 shows that IND1 "Investment in treatment and water management" (3.77), IND6 "Coverage with an individual water meter" (3.73), IND13 "Existence of water-related policies" (3.68), IND2 "Investment in the construction of new water supply networks" (3.64) and IND5 "Water supply tariff related to users' income" (3.59) were ranked as the highest among all indicators. In this category, the investment issue was ranked higher than in the environmental category which could be related to the fact that experts see these issues purely as an economic indicator. This indicator was followed by issues related to meters, policies, investments and tariffs. Most of these, except policy and investment issues, seem to have a direct impact on customers water consumption behaviour. Policy support and investments into new infrastructure projects are seen as vital support that is needed from the government. The close 
cooperation between individuals and the governments is quite visible from the economic point of view. The lowest-ranked indicators in this category are IND11 "Public education and awareness" (2.45), IND21 "Land/space requirement" (2.68), IND10 "Availability of efficient services for user complaints and requirements" (2.77), IND20 "Flexibility/adaptability of water systems" (2.91), IND16 "Separate storm-water systems" (2.91). The low ranked indicators in this category were the ones that seemed not to be related to finances. The concerning aspect in this category is related to the fact that education and awareness of the general public about water use is ranked the lowest. This is most likely related to the fact that the water-related experts did not see the connection between the user's behaviour with the economic sustainability of the infrastructure.

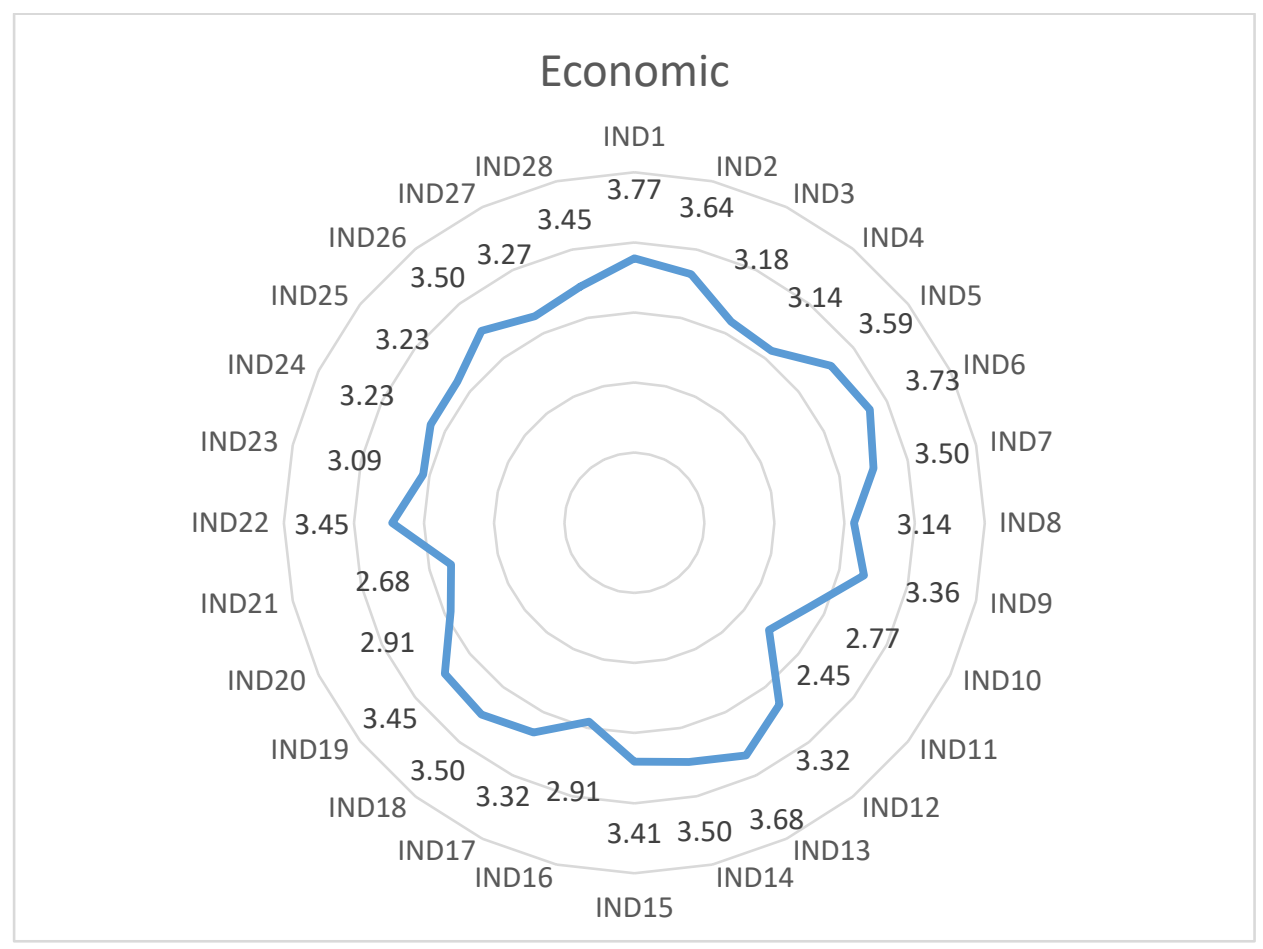

Figure 5. Ranking of economic indicators

As for the social indicators, Figure 6 indicates that IND24 "Chemical quality of drinking water" (4.14), IND12 "Incidence of water-related diseases" (4.09), IND5 "Water supply tariff related to users' income" (4.0), IND7 "Access to water supply" (3.86) and IND25 "Physical quality of drinking water" (3.86) were ranked as the highest among all indicators. Among the highly ranked indicators in this dimension is related to socially important issues such as water quality, diseases, income, accessibility. These are indeed important issues in terms of the overall level of social well-being of the Kazakhstani society and therefore were found to be sensitive in 
the case water theme. The lowest-ranked indicators in this category are IND20 "Flexibility/adaptability of water systems" (2.45), IND21 "Land/space requirement" (2.59), IND4 "Investment to research and development" (2.59), IND23 "Monitoring leakages and water loss from the water supply system" (2.64), IND17 "Aging of infrastructure assets" (2.82). Although, the majority of lowest-ranked indicators gained a value higher than 2.45 showing that all of these aspects are important but not as important as socially vulnerable topics.

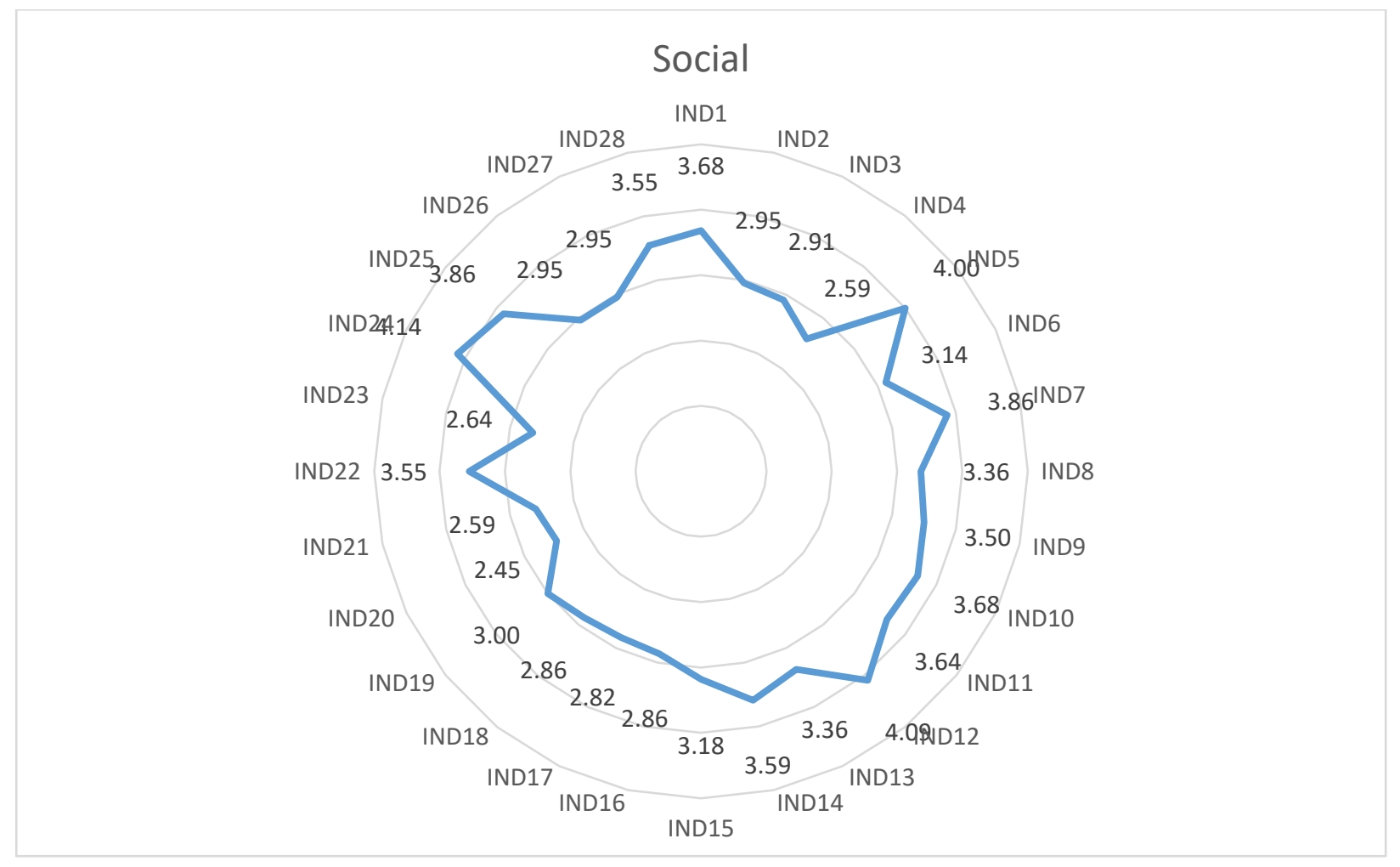

Figure 6. Ranking of social indicators

In the case of technological indicators, Figure 7 indicate that IND24 "Chemical quality of drinking water" (4.0), IND25 "Physical quality of drinking water" (3.91), IND17 "Aging of infrastructure assets" (3.68), IND26 "Water reclamation and reuse" (3.50) and IND19 "Capacity of drinking water reserves" (3.45) were ranked as the highest. As it already was noticed in the case of the environmental impact, the quality of water is of the highest priority in this category. The conditions of infrastructure assets and capacity of the water reserves also gained high grades due to the direct impact on the technological capacity of the water infrastructure. Notably, the water reclamation and re-use were ranked his as the concept of water recycling is not advanced in Kazakhstan due to the reluctance of the population to use water twice. The lowest-ranked indicators in this category are IND12 "Incidence of water-related diseases" (2.73), IND5 "Water 
supply tariff related to users' income" (2.73), IND4 "Investment to research and development" (2.73), IND1 "Investment in treatment and water management" (2.82), IND9 "Water availability per capita per day" (2.86). There were three indicators that received the lowest grade but were highly ranked in the other categories. The investment into R\&D is ranked low across all categories. This is most likely related to the generally poor development of science in Kazakhstan.

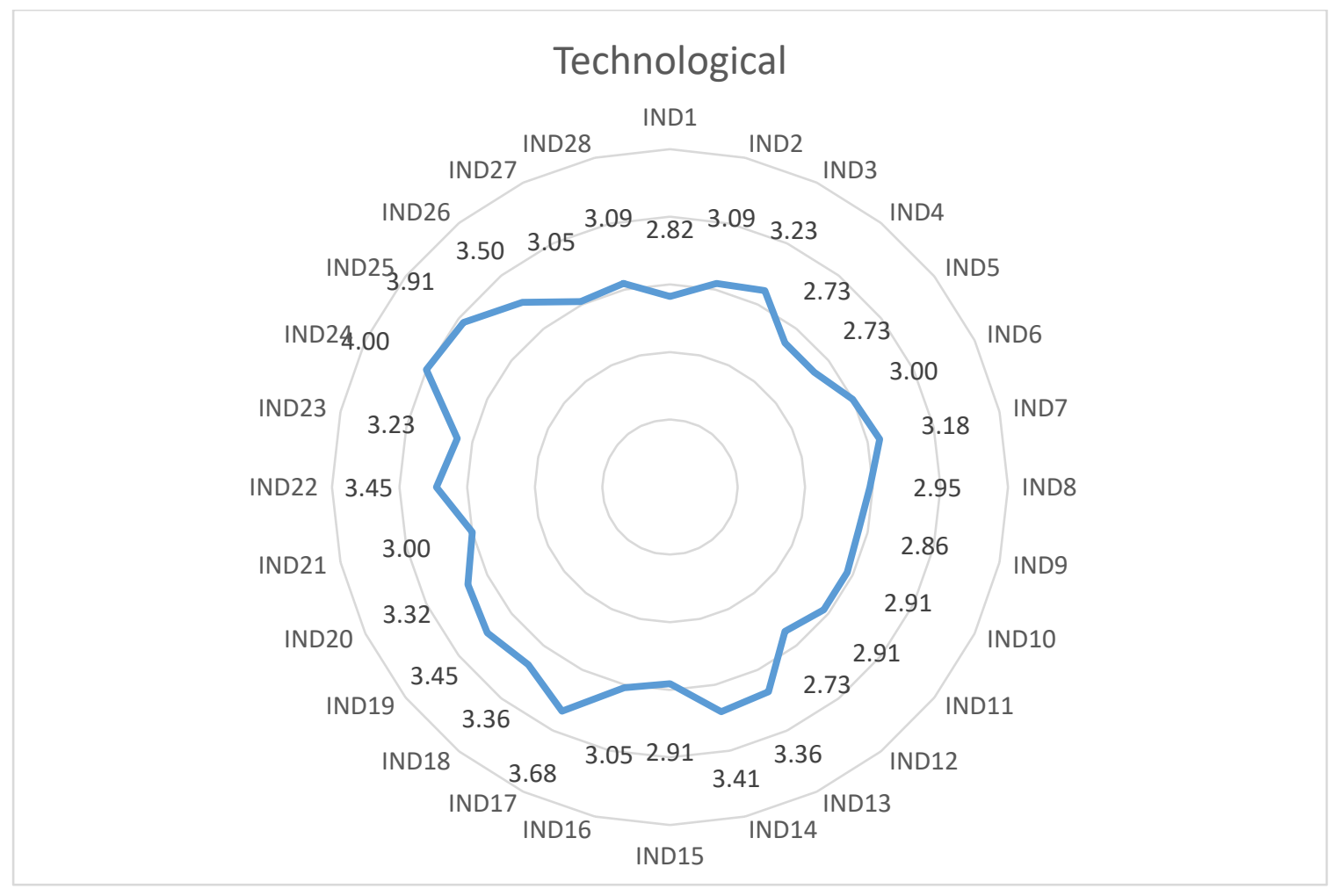

Figure 7. Ranking of technological indicators

Finally, Figure 8 indicates that IND6 "Coverage with an individual water meter" (3.32), IND18 "Efficient operation and maintenance of water infrastructure systems" (3.23), IND22 "Reliability/continuity of water supply" (3.23), IND14 "Compliance with the international water quantity and quality standards" (3.14) and IND17 "Aging of infrastructure assets" (3.09) were found to have the highest significance. The availability of meters was found to be important in terms of institutionalizing water sustainability. Other indicators were not mentioned in other categories, therefore, have a special value highlighting the issues that are usually neglected when sustainability is considered from the three pillars perspective (environmental and socio-economic dimensions). The lowest-ranked indicators in this category are IND16 "Separate storm-water systems" (2.59), IND27 "Local rainwater harvesting" (2.64), IND1 "Investment in treatment and 
water management" (2.64), IND25 "Physical quality of drinking water" (2.77), IND4 "Investment to research and development" (2.77). The lowest-ranked two indicators are related to water recycling which is not a common practice in Kazakhstan. The experts also underestimated them.

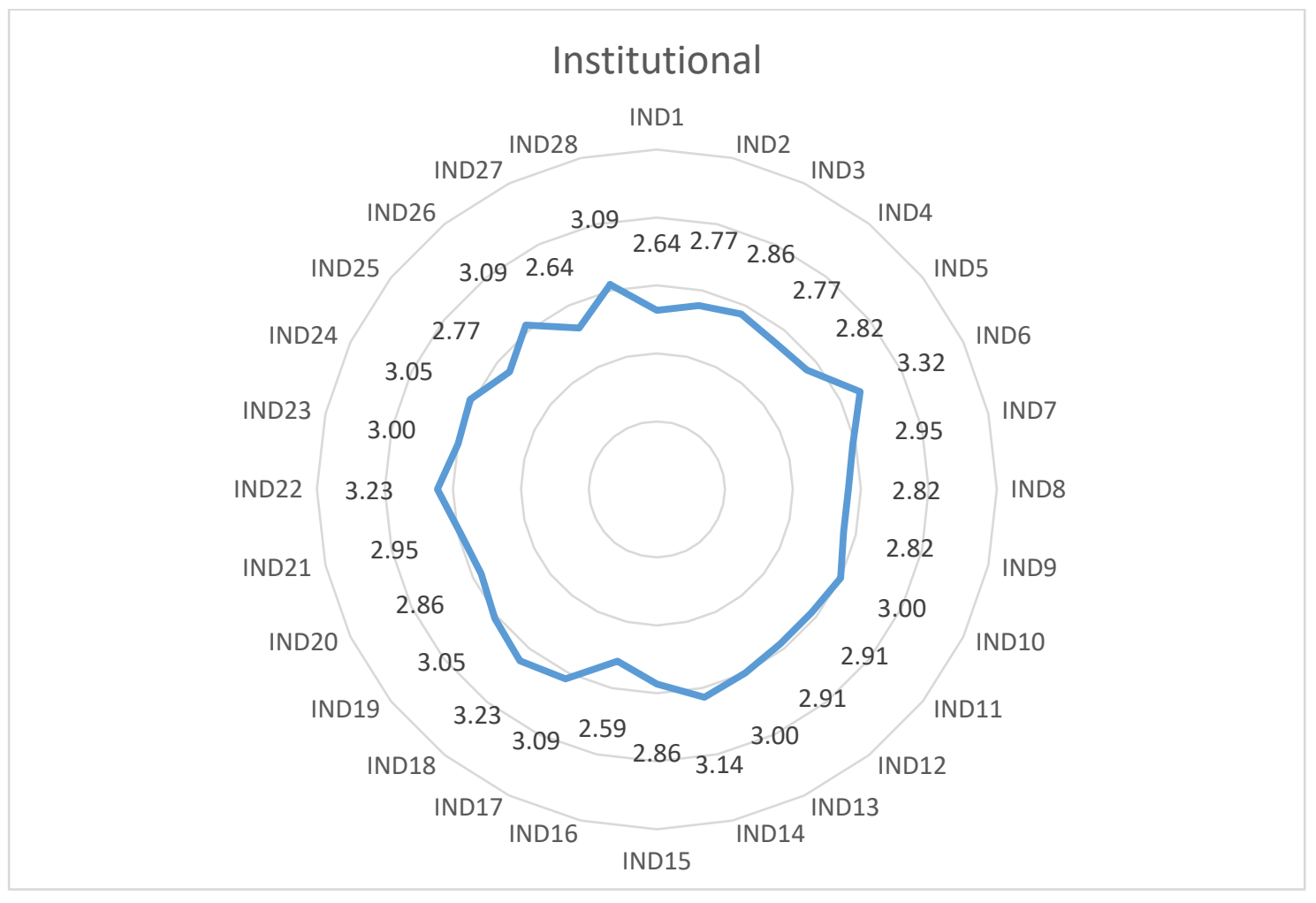

Figure 8. Ranking of institutional indicators

As it can be noted from the results presented above, some of the indicators came up multiple times among both the highest and lowest-ranked indicators across different sustainability dimensions. This provides additional insights into the importance of such indicators as their significance and insignificance is noted more than once. For example, IND24 "Chemical quality of drinking water" came up three times, IND25 "Physical quality of drinking water" three times, IND6 "Coverage with an individual water meter" twice, IND5 "Water supply tariff related to users' income" twice, IND17 "Aging of infrastructure assets" twice across the top five (5) highly ranked indicators in all 5 (five) sustainability dimensions. Considering these results, it could be stated that the water infrastructure-related experts are most concerned about the quality of drinking water. Both physical and chemical quality of water is found to be very highly ranked and seem to be important in terms of up to three sustainability dimensions. This might be directly linked with the current concerns regarding the quality of drinking water in Nur-Sultan city. Although tap water is considered good for drinking, there are occasional complaints about the smell and taste of the 
water, and this might be the reason why the majority of the population tend to use bottled, filtered or boiled water for drinking (KAZINFORM, 2018; Смайыл, 2019). The remaining three highly ranked indicators are linked to the availability of individual meters, adjusted tariffs and ageing infrastructure. Whereas the ageing infrastructure is an obvious argument especially due to the significant part of the city being built 30-40 years ago and requiring significant refurbishment not only of the water infrastructure but also the building stock in general, the individual meters and personalized tariffs are driving factors of general awareness and informed use of the water. These aspects require the highest attention from the relevant stakeholders during planning, operation and refurbishment of the water infrastructure system. The remaining twenty-three (23) indicators should also be considered with due attention and adopted based on their ranking in each respective sustainability dimension.

There were also trends noted while considering the least ranked indicators among which are IND4 "Investment to research and development" came up four times, IND1 "Investment in treatment and water management" three times, IND11 "Public education and awareness" twice, IND10 “Availability of efficient services for user complaints and requirements" twice, IND20 "Flexibility/adaptability of water systems" and IND21 "Land/space requirement" twice. All of these indicators seem to be of the second level of importance for the respondents. This is seen as a logically sensible scenario as they are more concerned about the basic requirements of sustainability such as quality, cost, and decent infrastructure. The least ranked indicators are seen to be more related to the scenarios when basic needs are covered and the stakeholders have extra time and resources for advancing the levels of water infrastructure sustainability.

In the third section of the questionnaire, the experts were asked to propose new indicators that could be suitable for future water infrastructure development in Nur-Sultan. Some of the participants proposed to include more indicators related to the institutional and social dimensions, such as "water filtration," "ratio of water purification channels to the total number," "public participation," "environmental coverage and revision of everyday habits with the media," "customer satisfaction with service" and "affordability/budget evaluation." The respondents were also asked to suggest ways how the provided indicators could be successfully implemented. Among the recommendations were "technological capabilities, collection and processing of melt snow water", "separation of drain and sewage must be separate", odours should be removed", "restoration and reuse of water", "transparency and technical KPI on operation efficiency", "asset 
management by renewing old pipes". These insights are essential to lead further refinement and development of an extended list of indicators.

This study aimed to identify the most important indicators from a literature review, prioritize them to understand their respective weightings, which, in turn, can serve as a decisionmaking tool for urban water infrastructure-related stakeholders. This tool can be used both for NurSultan city's urban infrastructure context as well as any developing country. The prioritized list of indicators can be a useful tool for all engaged stakeholders in the process of decision making related to water infrastructure. Moreover, the adopted in this study methodology could be used for any country with any level of development. It is assumed that although the different countries will have different outcomes due to their socio-economic, technological and institutional conditions, the general methodology of the study could be replicated at any city or a country level regardless of the geographical, demographic, political and economic parameters. Future research will take this tool further and test it as a system. Once the developed SI system is tested it could be further improved by comparing its results with the results obtained by the application of existing systems.

\section{Discussions and Conclusion}

The main aim of this study was to identify and assess the set of sustainability indicators that could help ensure sustainable urban water infrastructure development in Nur-Sultan, Kazakhstan. An extensive literature review was performed, and after refinement, a set of 28 indicators was developed. The indicators were further categorized based on the framework consisting of five sustainability categories (dimensions), specifically environmental, institutional, economic, social, and technological. The challenge faced here was to determine which indicators are more relevant and applicable for the assessment of the sustainability of urban water infrastructure systems in Nur-Sultan.

The next part of this research was to survey local water professionals and experts. The questionnaire consisting of three sections was designed and distributed among the experts, who have a high level of expertise in the field related to the water sector. The experts ranked each indicator in terms of its importance and compliance with each sustainability criterion. The results allowed identifying the most and least important indicators in each sustainability dimension. After thorough analysis similarities and differences across the most and least important indicators were noted. The findings of this study can be a useful tool for decision-making at the city and, perhaps, the country-level in ensuring the water infrastructure system is developed sustainably. There were 
some challenges in collecting the information from the survey. The distribution of questionnaires, contacting the stakeholders, and collecting the responses required a significant amount of time.

Overall, it can be concluded that the identified key indicators are intended to provide a comprehensive list of aspects that should be considered by all stakeholders engaged with the planning, development and operation of the water infrastructure system at an urban scale. In this study it was found that the highly rated indicators in all five categories were related to the chemical and physical quality of water, availability of individual water meters and water supply tariffs' adjustment to users' income, and issues of ageing infrastructure. The lowest rated indicators in all categories were primarily related to investments into research and development, water management and awareness, feedback systems and flexibility. These indicators are assumed to be related to the cases when basic needs are met and the stakeholders can dedicate time and resources for advancing the levels of water infrastructure sustainability. These findings show to the stakeholders what aspects are the most important aspects to consider and in what order they should be addressed. As the ranking was done in the context of urban water infrastructure, the information on the highest-ranked indicators would be useful for making decisions in the urban context.These indicators could also help inform the broader community about the progress of sustainable development. For example, the implementation of water indicators in Nur-Sultan could help to see how urban water infrastructure has progressed in achieving sustainability. A set of indicators could enhance understanding and actions towards sustainable development and serve as a useful tool for establishing better communication between different groups of stakeholders, including policymakers, scientists, water managers, and the public itself.

\section{References}

Asian Development Bank. (2018). Republic of Kazakhstan: Astana Integrated Water Master Plan Retrieved from https://www.adb.org/sites/default/files/projectdocuments/51353/51353-001-tar-en.pdf

Bagheri, A., \& Hjorth, P. (2007). A framework for process indicators to monitor for sustainable development: practice to an urban water system. Environment, Development and Sustainability, 9(2), 143-161.

Balkema, A. J., Preisig, H. A., Otterpohl, R., \& Lambert, F. J. (2002). Indicators for the sustainability assessment of wastewater treatment systems. Urban water, 4(2), 153-161. 
Brelih, M., Rajkovič, U., Ružič, T., Rodič, B., \& Kozelj, D. (2019). Modelling decision knowledge for the evaluation of water management investment projects. Central European Journal of Operations Research, 27(3), 759-781.

Cloquell-Ballester, V.-A., Cloquell-Ballester, V.-A., Monterde-Diaz, R., \& Santamarina-Siurana, M.-C. (2006). Indicators validation for the improvement of environmental and social impact quantitative assessment. Environmental Impact Assessment Review, 26(1), 79105.

Danilenko, A., Van den Berg, C., Macheve, B., \& Moffitt, L. J. (2014). The IBNET water supply and sanitation blue book 2014: The international benchmarking network for water and sanitation utilities databook: World Bank Publications.

Durdyev, S., \& Ismail, S. (2019). Offsite manufacturing in the construction industry for productivity improvement. Engineering Management Journal, 31(1), 35-46.

Durdyev, S., Ismail, S., \& Kandymov, N. (2018). Structural Equation Model of the Factors Affecting Construction Labor Productivity. Journal of construction engineering and management, 144(4), 04018007. doi:doi:10.1061/(ASCE)CO.1943-7862.0001452

Durdyev, S., \& Mbachu, J. (2011). On-site Labour Productivity of New Zealand Construction Industry: Key Constraints and Improvement Measures. Construction Economics and Building, 11(3), 18-33. doi:10.5130/AJCEB.v11i3.2120

Durdyev, S., \& Tokbolat, S. (2021). A quantified model for assessment of drivers of acquiring green buildings by potential clients. Environment, Development and Sustainability, 1-17.

Durdyev, S., Zavadskas, E. K., Thurnell, D., Banaitis, A., \& Ihtiyar, A. (2018). Sustainable construction industry in Cambodia: Awareness, drivers and barriers. Sustainability, 10(2), 392.

Fellows, R. F., \& Liu, A. M. (2015). Research methods for construction: John Wiley \& Sons.

García-Cáceres, R. G., Castañeda-Galvis, M. T., \& Suárez-Fajardo, J. F. (2019). Towards an efficient and sustainable planning of the drinking water supply chain. Journal of Cleaner Production, 230, 394-401.

Gilbert, A. (1996). Criteria for sustainability in the development of indicators for sustainable development. Chemosphere, 33(9), 1739-1748.

Harger, J., \& Meyer, F.-M. (1996). Definition of indicators for environmentally sustainable development. Chemosphere, 33(9), 1749-1775. 
Jensen, O., \& Wu, H. (2018). Urban water security indicators: Development and pilot. Environmental Science \& Policy, 83, 33-45.

Juwana, I., Muttil, N., \& Perera, B. (2012). Indicator-based water sustainability assessment-A review. Science of the Total Environment, 438, 357-371.

KAZINFORM. (2018). Какую воду пьют астанчане. Retrieved from https://www.inform.kz/ru/kakuyu-vodu-p-yut-astanchane_a3287189

Leflaive, X., \& Hjort, M. (2020). Addressing the social consequences of tariffs for water supply and sanitation.

Lehtonen, M. (2012). Indicators as an appraisal technology: Framework for analysing the policy influence of the UK Energy Sector Indicators. In Sustainable Development, Evaluation and Policy-Making: Edward Elgar Publishing.

Lundin, M. (2003). Indicators for measuring the sustainability of urban water systems: A life cycle approach: Citeseer.

Marques, R. C., da Cruz, N. F., \& Pires, J. (2015). Measuring the sustainability of urban water services. Environmental Science \& Policy, 54, 142-151.

Milman, A., \& Short, A. (2008). Incorporating resilience into sustainability indicators: An example for the urban water sector. Global Environmental Change, 18(4), 758-767.

Pires, A., Morato, J., Peixoto, H., Botero, V., Zuluaga, L., \& Figueroa, A. (2017). Sustainability Assessment of indicators for integrated water resources management. Science of the Total Environment, 578, 139-147.

Seaford, C. (2013). The multiple uses of subjective well-being indicators. Social indicators research, 114(1), 29-43.

Singh, R. K., Murty, H. R., Gupta, S. K., \& Dikshit, A. K. (2009). An overview of sustainability assessment methodologies. Ecological Indicators, 9(2), 189-212.

Smith, E., \& Zhang, H. (2004). Formulating Key Water Quality Indicators for Sustainable Water Resources Development, WEFTEC'04, October 2-6, New Orleans, LA. In.

Spangenberg, J. H. (2008). Second order governance: learning processes to identify indicators. Corporate Social Responsibility and Environmental Management, 15(3), 125-139.

Spiller, M. (2016). Adaptive capacity indicators to assess sustainability of urban water systemsCurrent application. Science of the Total Environment, 569, 751-761. 
Sullivan, G. M., \& Artino Jr, A. R. (2013). Analyzing and interpreting data from Likert-type scales. Journal of graduate medical education, 5(4), 541-542.

Tavakol, M., \& Dennick, R. (2011). Making sense of Cronbach's alpha. International journal of medical education, 2, 53.

Tokbolat, S., Karaca, F., Durdyev, S., \& Calay, R. K. (2019). Construction professionals' perspectives on drivers and barriers of sustainable construction. Environment, Development and Sustainability, 22, 4361-4378. doi:10.1007/s10668-019-00388-3

Venkatesh, G., \& Brattebø, H. (2013). Typifying cities to streamline the selection of relevant environmental sustainability indicators for urban water supply and sewage handling systems: a recommendation. Environment, Development and Sustainability, 15(3), 765782.

Waas, T., Hugé, J., Block, T., Wright, T., Benitez-Capistros, F., \& Verbruggen, A. (2014). Sustainability assessment and indicators: Tools in a decision-making strategy for sustainable development. Sustainability, 6(9), 5512-5534.

Смайыл, М. (2019). Качество воды в Нур-Султане проверят после жалоб в соцсетях. Retrieved from https://tengrinews.kz/kazakhstan_news/kachestvo-vodyi-nur-sultaneproveryat-jalob-sotssetyah-380245/ 